\title{
Research on Dependences of Railway Infrastructure Capacity
}

\author{
Jozef GAŠPARÍK, Borna ABRAMOVIĆ, Vladislav ZITRICKÝ
}

\begin{abstract}
Following the liberalisation of the railway infrastructure, the non-discriminatory approach to each railway undertaking is necessary, including the issue of the train paths provision in terms of the railway infrastructure capacity. Expression and provision of the throughput capacity of the railway network by absolute number of train paths appear to be inadequate and inaccurate at first glance. There are many ways of calculating the capacity of rail infrastructure, as well as several ways of expressing it. The paper describes the testing of the railway infrastructure capacity in a computer based simulation model, which provides results for further research in the area of this issue. Two hypotheses oriented towards the research on the linear dependence of capacity on the number of train paths as well as towards the need for capacity estimation for a whole track or for only one block section are tested.
\end{abstract}

Keywords: assigned; capacity; infrastructure; railway; relativity; train path; testing

\section{INTRODUCTION}

For the optimal utilisation of the railway infrastructure capacity it is necessary to calculate it properly in terms of a liberalised access to the infrastructure. An infrastructure manager is obligated to ensure a non-discriminatory approach for railway undertakings, including the issue of the train paths allocation.

A variety of simulation models used for capacity estimation accept different input parameters and are able to answer free capacity issues in a very short time ("quick response").

The main aim of the research is based on the following assumptions:

- Customers' requirements are constantly changing and evolving in time and they exceed the opportunities of current methodologies to give a quick response to railway infrastructure capacity estimation;

- There is an ensured non-discriminatory access to the railway infrastructure for all railway undertakings;

- The number of ordered "ad hoc" train paths will constantly grow, mainly in freight railway transport.

Train paths should satisfy the customer's time requirements; in this situation a railway undertaking plays the role of a customer. Railway undertakings have legitimate requirements for the infrastructure manager, mainly in terms of the quality of railway infrastructure, stability of charges, and flexibility of capacity allocation. Infrastructure managers and railway undertakings should cooperate on the minimisation of operating irregularities and increase the railway network capacity, while the main quality elements are safety, capacity, speed, cost effectiveness, track connections, and also helpfulness to customers at railway stations [2].

Research on railway capacity must concentrate on its dependence on the heterogeneity of train paths in the timetable and the achievement of train path efficiency. The capacity issues are linked to the measurement of the overall railway infrastructure effectiveness [8].

\section{THE AIM OF THE RESEARCH}

In the railway infrastructure capacity research (focusing on its change from the train mix), the following hypotheses have been established:

Hypothesis I: We suppose that the dependence of railway infrastructure capacity utilisation on the number of inserted train paths is not linear.

Hypothesis II: We suppose that railway infrastructure capacity utilisation can be directly and accurately assessed only at each particular block section in a certain time frame.

The aim of the research is to verify the postulated hypotheses using an appropriate methodology and appropriate simulation processes. The operating performance can be determined based on the throughput capacity of the least productive infrastructure equipment within deterministic operating conditions. On the other hand, under stochastic operating conditions, it is necessary to solve this problem based on the knowledge of queuing theory as a cascade of queue systems. In doing so, it is concluded that the operating performance will be lower than the performance of the least productive equipment [6, 10].

Analytical methodologies, which include approaches for the detection of the infrastructure equipment capacity, also use inaccurate average train paths (mainly through freight trains) and search for the boundary inter-station section as a system bottleneck. The final result - the socalled practical throughput capacity of this critical section - is then declared as a summary for the whole line section, namely, in absolute terms, the number of trains within a certain time window (usually 24 hours) [2, 4, 10].

However, this approach does not consider the train paths that cannot pass through the boundary section, nor does it consider the daily and hourly mix of train paths on the train traffic diagram.

The International Union of Railways (UIC) made steps to unify these methodologies in the leaflet issued as UIC Code 406 "Capacity" [13]. The methodology for the estimation of railway infrastructure capacity in the final solution of real infrastructure capacity is lacking in this leaflet. The result of the capacity analysis is expressed only as the final statement of feasibility or unfeasibility of the train traffic diagram $[2,3]$. 
It provides information about capacity consumption according to the compression method. There is a need to estimate the total occupancy time in a defined line section. The graphical compression of train paths is repeated after inserting the added train paths. [1] It, however, does not provide an answer to how many paths can be added considering the quality and safety of the railway transport operation in each block section. [2] Accordingly, even in that one containing a free time window for inserting new train paths which have remained there after the compression (see Fig. 1).

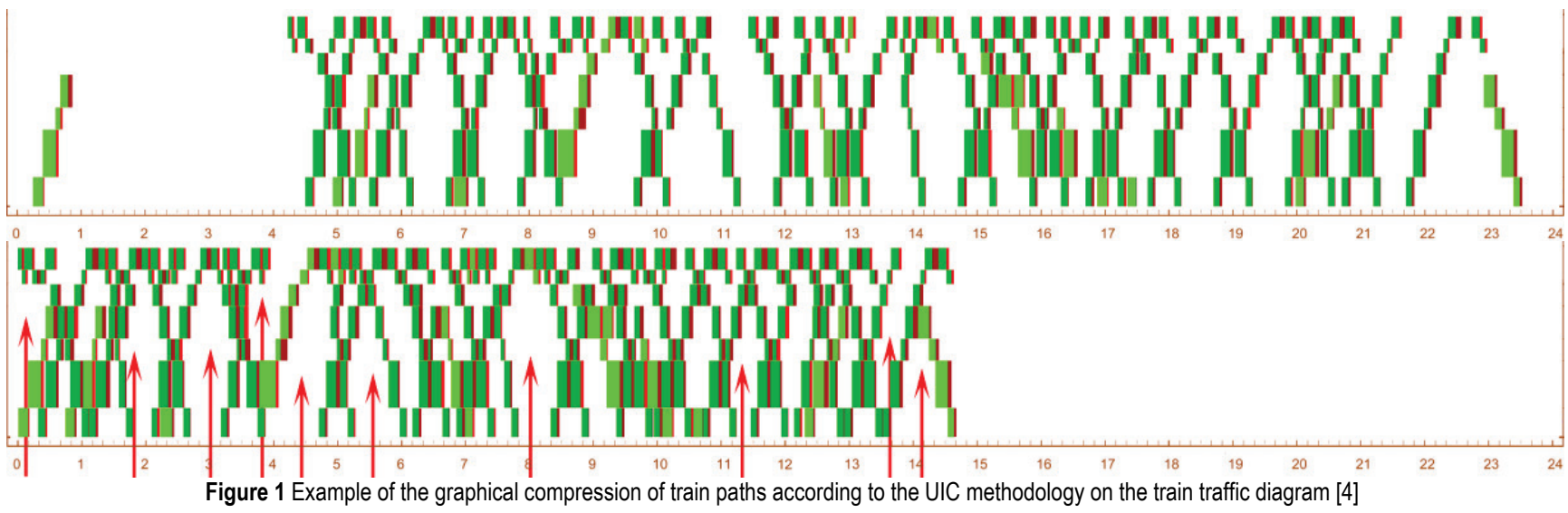

The key question is how to estimate the occupation time. Average occupation times per train in principle consist of the travel time in the boundary section and the operation interval time [4]. Depending on collision points, the operating intervals are divided into station intervals and track intervals [2]. Operating interval standards are defined separately for each station and for each direction of adjunct tracks in cases where the simultaneous running of such trains is not allowed.

It is necessary to research this topic considering the increasing stochastic demand for occasional "ad hoc" train paths, mainly due to frequent changes in the transport market. These "ad hoc" paths differ in terms of many input parameters and can often be related to specific originating and end traffic points. On the other hand there is a problem with the provision of free as well as cancelled train paths to other railway undertakings. The added trains have different technical parameters, leading to different travel times $[11,12]$.

Infrastructure managers have to clearly determine and disclose information about the railway infrastructure capacity while maintaining principles of a nondiscriminatory access to the infrastructure. It is needed to find a simple and transparent way how to identify and show the final values of railway infrastructure capacity and consequently how to offer and allocate it within the train paths marketing process of infrastructure managers.

\section{THE CHARACTERISTICS OF THE SIMULATION MODEL}

In the complex process of capacity allocation it is necessary to know the real value of the railway infrastructure capacity, which means its quantitative indicator respecting qualitative traffic operation parameters. This is the main precondition for the infrastructure manager to offer train paths to authorised applicants and thus to ensure the access to the railway infrastructure. Subsequently, when the railway undertaking meets the required conditions, the infrastructure manager proceeds to direct allocation of train paths to the timetable (in the timetabling process of preparation and construction of the train traffic diagram), but mainly in the operative management of railway traffic. The "ad hoc" train paths differ in their technical parameters and requirements. This allocation process also demands the shortest answer from the infrastructure manager as well as transparent reasons for acceptance or refusal of the requirement by the railway undertaking. [11]

Nowadays, a variety of simulation tools are used for the timetabling process, which can work with a lot of variables or randomly generated irregularities in the train traffic. These tools are able to include the correlation between traffic operation and infrastructure capacity, and emphasis is constantly put on the safety and quality of traffic operation [12].

The simulation software RailSys (developed by RMCon) was used to test the dependence of the capacity used on the number and kinds of train paths in the train traffic diagram. RailSys is a synchronic simulation tool, which concurrently simulates all the steps within the network in short time frames (generally one sec.). This complex simulation software works in three basic model views [7]:

- macroscopic (railway infrastructure network - nodes and edges);

mesoscopic (concretised on the track section);

microscopic (local and detailed).

It offers a wide range of tools and possibilities for creating a new operational model that can approach reality as closely as possible and that provides relevant and valuable data outputs. The software contains a variety of modules, for example the infrastructure manager module, multi-access module, timetable construction module, vehicles and trainsets module, infrastructure capacity analysis module, planning module, operative simulation module, evaluation module, vehicle running module, outputs module, etc. This research considered the singletrack line No. 140/141 of Zeleznice Slovenskej republiky (ŽSR - Railways of Slovak Republic) with a length of 35.4 $\mathrm{km}$ from Leopoldov to Nitra. The testing on this line with various train mixes was done for a real timetable. 
In the preparation of the research, a simulation model with the following steps was created:

- $\quad$ specific modelling of the infrastructure of the selected line (profile of line and track alignment, safety device, static speed profile, adjacent infrastructure);

- model customisation into three model views;

- creating the database of the park of vehicles used (locomotives, wagons, train units), which means inserting tractive power diagrams of standard locomotives and other train units, choosing parameters, etc.;

- creating train sets of vehicles for selected train categories;

- inserting train paths and constructing the real train traffic diagram;

- progressive simulation of operations and comprehensive debugging of the model;

- creating variant train traffic diagrams (there were seven variants in the research by inserting added train paths to certain timeslots);

- creating possible disruptions in the traffic operation (there were twenty variants in the research);

- the process of simulation of the prepared scenarios;

- data collection and the final evaluation.

\section{TESTING OF THE MODEL}

The main idea of the capacity testing in the simulation software (within the progressive methods of railway infrastructure capacity detection) was to verify the hypothesis concerning the relation between the railway infrastructure capacity consumption and the number and mix of train paths. The railway infrastructure capacity consumption and the number of train paths are not expected to be linearly related. This is the first precondition, which can show a lack in the analytic methodology used on ŽSR [2], Sprava zeleznicni dopravni cesty (SŽDC), or Hrvatske zeljeznice (HŽ) [9], as well as in the UIC methodology used in the RailSys capacity module.

In the simulation of the traffic operation, final capacity consumption, and added train paths inserted (with regard to the consideration of the mix of train paths and the expected results according to the UIC methodology) eight variants were realised:

- Var0: the basic variant of the train traffic diagram, the data is taken from the real life timetable;

- Var1: twice the number of fast trains (on the Leopoldov-Zbehy track section) compared to Var0;

- Var2: twice the number of regional trains (on the Leopoldov-Nitra track section) compared to Var0;

- Var3: twice the number of fast trains and passenger trains (in the period if possible) compared to $\operatorname{Var} 0$;

- Var4: four times the number of through freight trains as well as twice the number of local service trains;

- Var5: twice the number of fast trains and through freight trains (on the Leopoldov-Zbehy track section) compared to Var0;

- Var6: identical to Var0; links between connecting trains are incorporated; the stability of the train traffic diagram is tested;

- Var7: a special variant that works with one category of train paths only, their relative positions, their route character on the track section, and the calculation of inserted train paths.

The simulation testing of the designed variants shows the robustness of the pre-constructed train diagrams as the models of train operation.

Var0 is the basis for all of the following variants. The trains run on time in accordance with the train traffic diagram, without delay at each control point (operating point). It also serves for verification of the traffic plan being without conflict. The final capacity consumption is projected as a point of linear dependence. This model contains 49 train paths on the Luzianky-Nitra track section and 57 train paths on the Luzianky-Leopoldov track section. This means that the total number of mixed train paths is 81 (42 in the odd direction and 39 in the even direction of traffic), of which $88 \%$ are passenger train paths. This variant does not consider any optional trains, locomotive trains, or private siding trains.

Varl is a variation of Var0 with twice the number of fast trains. After the addition of fast train paths, a two-hour period of fast trains was created; thus train paths were inserted into certain timeslots. After running the simulation, a test was performed to determine that no system breakdown (deadlock) occurred because of the need for crossings on the single-line track. The timetable was robust after increasing the number of switchmen at the Risnovce station due to the need for train crossings. This variant of the time traffic diagram contains 89 train paths $(46 / 43)$, of which $89 \%$ are passenger train paths.

Var2 is a variation of the basic variant Var0 with twice the number of passenger trains. The original train paths were respected by inserting passenger train paths. A onehour period of passenger trains could not be created, because a system deadlock occurred during the testing of the stability of the train traffic diagram. The most corrupt period was in the most occupied section of the LuziankyNitra track. No connections to linked lines were kept. This variant contains 97 train paths (50/47), of which $90 \%$ are passenger train paths.

Var3 proceeds from the basic Var0, but has twice the number of fast and passenger trains. In some cases it was not possible to construct a periodic timetable for passenger trains. The simulation was prematurely stopped. This variant contains 105 train paths, of which $91 \%$ are passenger train paths.

Var4 is patterned on the basic Var0, but has four times the number of through freight trains and twice the number of local service trains. Through freight trains were inserted every four hours (at intervals of 4 hours), and local service trains were inserted every two hours, in order not to disturb passenger trains. While the simulation was running, only inserted freight train paths were adjusted according to their importance and priority. This variant contains 107 train paths $(55 / 52)$, of which $66 \%$ are passenger train paths.

Var5 is a variation of the basic Var0 with twice the number of fast trains and through freight trains. The same principles are applied in the correction of train paths as in previous variants. The total number of train paths in this variant is $95(49 / 46)$, of which $83 \%$ are passenger train paths.

Var6 is based on the basic Var0 but it emphasises the connection between passenger trains and linked tracks (in 
the Luzianky and Zbehy stations). Based on this, the stability of the train traffic diagram was tested. Twenty possible input delays were tested and the ability of the train traffic diagram to eliminate input delay was examined. These train delays were generated randomly in testing. A negative exponential distribution was used for interruption of the train traffic diagram (for example due to the entry of a train into the system, train arrival at or departure from the traffic point, train dwell, exceeding of running times, etc.).

Var7 is a specific variant with through freight trains and it focuses on the railway infrastructure capacity consumption depending on the relative position, train character (even-number train takes priority over odd- number train, train crossing in another station), and the possibilities for inserting additional train paths considering UIC methodology.

\subsection{Dependence Analysis of Capacity Consumption Development}

The data processing and evaluation obtained from the testing of the consumed capacity depending on the number and type of train paths was divided into two phases due to the fundamentally different character of some of the tested variants.

Table 1 Data evaluation of the first phase of simulation testing

\begin{tabular}{|c|c|c|c|c|c|c|c|c|c|c|}
\hline \multirow{3}{*}{ Variant } & \multicolumn{3}{|c|}{ Time values per line } & \multicolumn{4}{|c|}{ Capacity for two-way traffic } & \multicolumn{3}{|c|}{ Capacity for one-way traffic } \\
\hline & $\begin{array}{c}\text { Time } \\
\text { window }\end{array}$ & Delay & $\begin{array}{c}\text { Average } \\
\text { delay per } \\
\text { train }\end{array}$ & $\begin{array}{l}\text { Occupation } \\
\text { time }\end{array}$ & $\begin{array}{l}\text { Number of } \\
\text { train paths } \\
\text { (even/odd) }\end{array}$ & $\begin{array}{l}\text { Number } \\
\text { of train } \\
\text { paths }\end{array}$ & $\begin{array}{c}\text { Capacity } \\
\text { consumption }\end{array}$ & $\begin{array}{l}\text { Occupation } \\
\text { time }\end{array}$ & $\begin{array}{l}\text { Number } \\
\text { of train } \\
\text { paths }\end{array}$ & $\begin{array}{c}\text { Capacity } \\
\text { consumption }\end{array}$ \\
\hline & (s) & $(\mathrm{s})$ & (s) & $(\mathrm{s})$ & (trains) & (trains) & $(\%)$ & (s) & (trains) & $(\%)$ \\
\hline Var0 & 86,400 & 1 & 0 & 48,836 & $42 / 39$ & 81 & $56.5 \%$ & 18,182 & 42 & $21.0 \%$ \\
\hline Var1 & 86,400 & 22,144 & 36 & 51,867 & $46 / 43$ & 89 & $60.0 \%$ & 17,905 & 46 & $20.7 \%$ \\
\hline Var2 & 86,400 & 49,852 & 65 & 83,083 & $50 / 47$ & 97 & $96.2 \%$ & 25,409 & 50 & $29.4 \%$ \\
\hline Var3 & 86,400 & 77,897 & 95 & 68,511 & $54 / 51$ & 105 & $79.3 \%$ & 28,397 & 54 & $32.9 \%$ \\
\hline Var4 & 86,400 & 66,444 & 91 & 66,462 & $55 / 52$ & 107 & $76.9 \%$ & 32,888 & 55 & $38.1 \%$ \\
\hline Var5 & 86,400 & 49,056 & 74 & 55,925 & $49 / 46$ & 95 & $64.7 \%$ & 19,610 & 49 & $22.7 \%$ \\
\hline
\end{tabular}

In the first phase of the traffic operation variants testing the differences in the railway infrastructure capacity consumption for heterogeneous train paths in two-way traffic as well as one-way traffic were compared. These variants were compared with the capacity consumption for Var0, which is assumed to be a point on the linear dependency (Tab. 1). An analysis of the relationship between all variants and trend curve (second-order polynomial) was made in two variants. In Fig. 2 there was made a comparison between the capacity utilisation in a heterogeneous two-way train traffic diagram. In Fig. 3 there was made a comparison between the capacity utilisation in a heterogeneous one-way train traffic diagram. Nevertheless, a consumed capacity curve does not have to be expressed as a dependence of the secondorder polynomial.

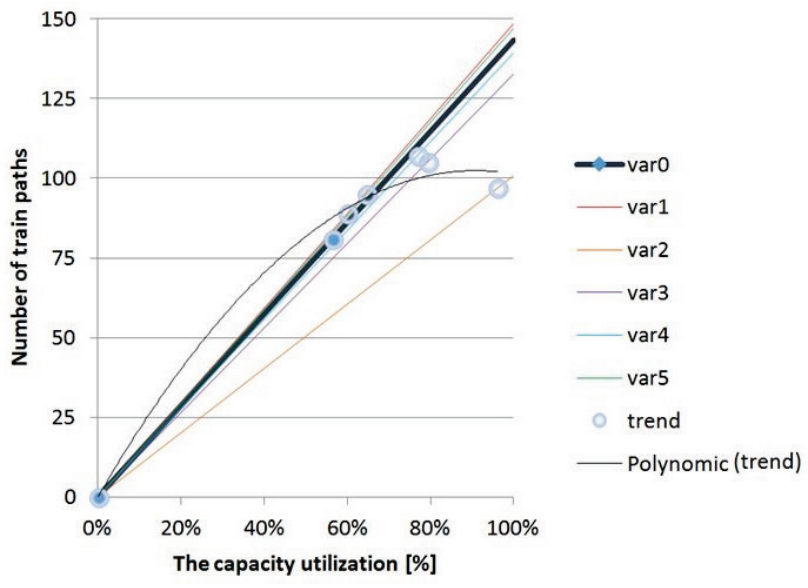

Figure 2 The capacity utilisation in a heterogeneous two-way train traffic diagram

Although in a heterogeneous time traffic diagram, the consumed capacity curve is not linear, considering the diversity of train paths, it is necessary to clarify that it is not the same even in homogeneous time traffic diagrams with the same or related train paths. Various organised train paths of identical trains, their combination, or the variation of quality parameters results in different levels of capacity consumption (following UIC methodology), as can be seen in Fig. 4, while the number of inserted train paths is less than in the basic variant. This is due to the fact that homogeneous through freight train paths in Var7 are slower than passenger train paths in a very heterogeneous Var0. This means that the reciprocal order of train paths and their own influence on the track section have a big influence on the capacity consumption, among other factors.

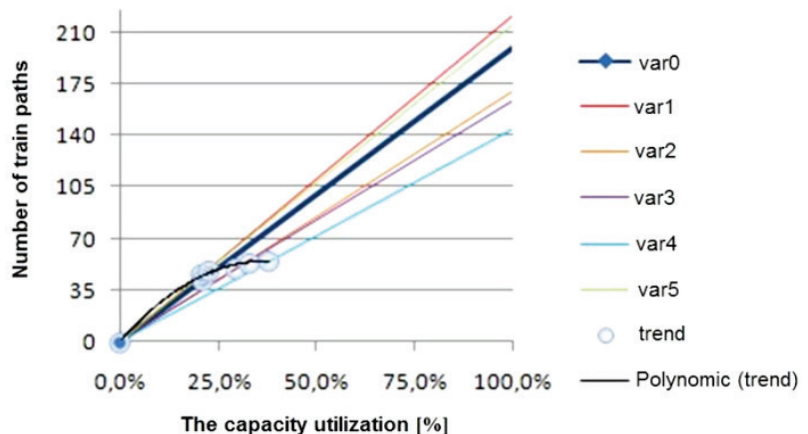

Figure 3 The capacity utilisation in a heterogeneous one-way train traffic diagram

In the simulation of traffic operations, the impact of an input delay was also tested. Input and output values of delay per time period were monitored. A stability test was conducted by sequential application of 21 scenarios for disruption of the train traffic. Differences in the scenarios are caused with the type of disruption of a train path, location in an infrastructure section and probability distributions. The RailSys software algorithm uses an exponential negative probability distribution (marked as NegExp1, NegExp2 and NegExp3) for random selection of train paths that are loaded by disruption. 


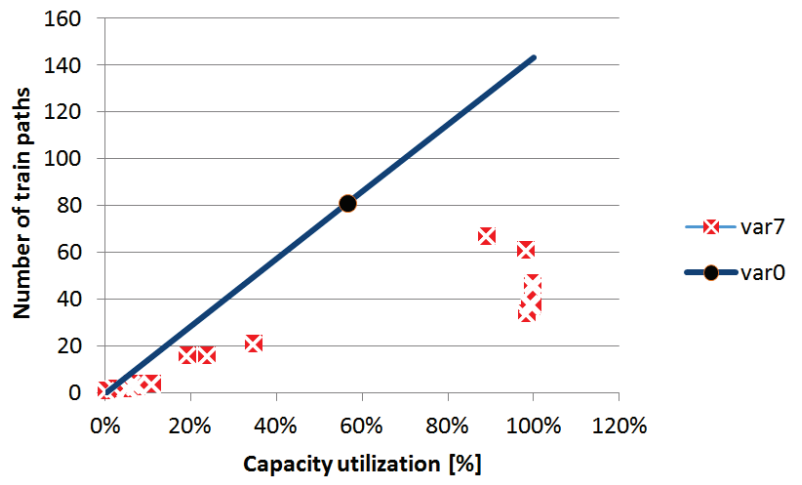

Figure 4 The capacity utilisation in a homogenous two-way train traffic diagram

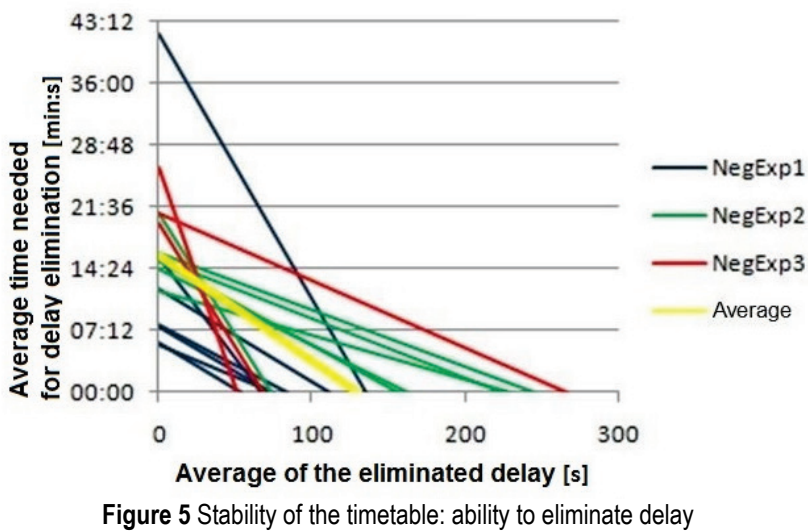

The result is the dependence of an average time needed for delay elimination on the average eliminated delay per one train path (Fig. 5). Based on these analysis results it is clear that all the variants with positive simulation runs show an effect in the elimination of interruptions in the traffic operations.

\subsection{The Analysis of the Capacity Utilisation in a Block Section}

The base for the verification of the second hypothesis is the same analysed train traffic diagram (including simulation runs). The value of capacity consumption changes with each added train path. The capacity consumption was determined according to the new methodology of the Department of Railway Transport, University of Žilina $[2,4,5]$. It uses a graphical approach for determining the capacity consumption, either by a direct determination of occupation time, or determination of the computing framework area in one block section [2], [11]. The indicator of railway infrastructure capacity consumption $\left(C_{S}\right)$ is defined as the percentage rate of the sum of time consumption [running time $\left(t_{j}\right)$, operational time interval corresponding to a train path within a block section $(P I)$, inapplicable time (lost and unavailable for added paths) in the block section $\left(t_{x}\right)$,and computing time $(T)$ ]. These capacity consumption times show partial capacity consumption. For details about the determination of operation times see, for example references $[2,4]$.

The results of changes in infrastructure capacity are shown in Tab. 2. The examined variants consider the insertion of two train paths but with a different kind of path in each variant. The first variant has a different change of capacity consumption $(0.3 \%)$ compared to the second and fourth variants $(0.9 \%)$. The other variants, which seem to be identical, show different changes in capacity consumption in particular block sections $(1.7,0.8,0.7$, $1.1 \%)$.

\begin{tabular}{|c|c|c|c|c|c|c|}
\hline \multirow[b]{3}{*}{ Blocking section } & \multicolumn{6}{|c|}{ Capacity [\%] } \\
\hline & \multicolumn{3}{|c|}{ Consumed $\left(\mathbf{t}_{\mathrm{j}}+\mathrm{t}_{\mathrm{pI}}+\mathrm{t}_{\mathrm{x}}\right)$} & \multicolumn{3}{|c|}{ Free $\left(t_{v}\right)$} \\
\hline & $A_{-}$ & \multirow{3}{*}{ - $\frac{\text { B }}{48.75}$} & - & $A_{-}$ & \multirow{3}{*}{ - } & \multirow{2}{*}{$-{ }_{-}$} \\
\hline Nitra - Mlynárce & 55.19 & & & 44.81 & & \\
\hline Mlynárce - Lužianky & 42.31 & & & 57.69 & & \multirow{6}{*}{65.81} \\
\hline Lužianky - Zbehy & 23.88 & \multirow{5}{*}{28.36} & & 76.12 & \multirow{5}{*}{71.64} & \\
\hline Zbehy - Alekšince & 31.00 & & 34.19 & 69.00 & & \\
\hline Alekšince - Rišňovce & 22.65 & & & 77.35 & & \\
\hline Rišňovce - Hlohovec & 38.46 & & & 61.54 & & \\
\hline Hlohovec - Leopoldov & 25.81 & & & 74.19 & & \\
\hline
\end{tabular}

The analysis refers to the need to determine the capacity in each block section separately, where it is possible to determine the following capacity changes exactly when the traffic performance is changing. Therefore, Hypothesis II was accepted.

\section{CONCLUSION}

The main task in the management of railway infrastructure capacity is to ensure the efficient use of railway infrastructure. Based on the analysis of infrastructure and operating concepts the factors that influence the use of the railway infrastructure can be determined.

In the case study, the research was conducted by testing hypotheses about the behaviour of dependence of the consumed capacity on the number of inserted train paths. The hypothesis regarding the impact of the mix of paths on consumption capacity was tested, too. This research was conducted by examining the capacity for homogeneous and heterogeneous time traffic diagrams in several variants including train traffic diagrams with mixed traffic and with one type of train path.

The research on the railway infrastructure capacity brings these important findings:

- The capacity cannot be expressed in exact or absolute numbers;

- The formulation of the average and type elements causes deformation of the results;

- There is no sufficient justification for performing path compression and inserting additional paths;

- The capacity consumption and the number of train paths are not linearly related;

- The characterisation of the capacity is the size and ratio of time quantities;

- Values determined in the UIC leaflet can be exceeded when the amount of buffer time is ensured

- The current methodologies do not cover the diversity of traffic operations;

- The current methodologies do not cover the diversity of computing periods;

- The current methodologies do not cover the diversity of track sections;

- A specific mix of train paths and their relative positions in the train traffic diagram are crucial to the capacity estimation;

- It is necessary to estimate the capacity in each block section separately; 
- Mutual placement of the paths is a new serious problem.

A retrospective assessment of the compliance time traffic diagram calls for the drawing of conclusions on the construction of the time traffic diagram and insertion of paths. The charges for the use of the railway infrastructure should reflect the intended path and its reverse evaluation. Other aspects, such as determination of the performance of additional paths, penalties for deviations from observance of the time traffic diagram, etc., can be explored.

\section{Acknowledgements}

The paper is supported by the VEGA Agency under Project 1/0095/16 "Assessment of the Quality of Connections on the Transport Network as a Tool to Enhance the Competitiveness of Public Passenger Transport System", which is being carried out at the Faculty of Operations and Economics of Transport and Communication, University of Žilina.

\section{REFERENCES}

[1] Hansen, I. A. \& Pachl, J. (2014). Railway Timetabling \& Operations. Analysis - Modelling - Optimisation Simulation - Performance Evaluation. $2^{\text {nd }}$ ed. Eurailpress.

[2] Gašparík, J. \& Šulko, P. (2016). Technology of Railway Transport - Line Transport Process (in Slovak). EDIS University of Zilina.

[3] Burdett, R. L. (2016). Optimisation models for expanding a railway's theoretical capacity. European Journal of Operational Research, 251(3), 783-797. https://doi.org/10.1016/j.ejor.2015.12.033

[4] Gašparík, J., Abramović, B., \& Halás, M. (2015). New graphical approach to railway infrastructure capacity analysis. Promet-Traffic \& Transportation, 27(4), 283-290. https://doi.org/10.7307/ptt.v27i4.1701

[5] Gašparík, J. \& Zitrický, V. (2014). Aspects of railway capacity and occupation time estimation. Journal of Civil Engineering and Architecture, 8(3), 67-76. https://doi.org/10.17265/1934-7359/2014.03.007

[6] Gašparík, J., Šulko, P., \& Kolář, J. (2012). New aspects in railway traffic intervals computing. Horizons of Railway Transport, 1(3), 46-52.

[7] Malavasi, G., Molková, T., Ricci, S., \& Rotoli, F. (2014). A synthetic approach to the evaluation of the carrying capacity of complex railway nodes. Journal of Rail Transport Planning \& Management, 4(1), 28-42. https://doi.org/10.1016/j.jtpm.2014.06.001

[8] Nikolić, I., Arsovski, S., Erić, M., Vujičić, S., Manojlović, G. \& Jovanović, J. (2016). Overall railway infrastructure effectiveness as a quality factor for Serbia railways. Tehnički vjesnik, 23(2), 547-554. https://doi.org/10.17559/TV-20130918010102

[9] Abramović, B. \& Šimunec, I. (2012). Optimization of railway traffic on Varaždin-Golubovec railway line. Proceedings of the Int. Conference Euro-Žel 2012, Žilina, 714.

[10] Kendra, M., Babin, M., \& Šulko, P. (2013). Interaction between railway infrastructure parameters and quality of transportation services. Proceedings of the Int. Conference BulTrans-2013, Sofia, 95-97.
[11] Halás， M., Gašparík，J., \& Pečený, L. (2013). Rail infrastructure capacity research as a part of train paths allocation. Proceedings of the Int. Symposium EURO - ŽEL 2013, Žilina, Brno: Tribun EU, 78-85.

[12] Halás, M., Gašparík, J., Pečený, L., Blaho, P. (2012). Progressive methods of detecting railway infrastructure capacity (in Slovak). Železničná doprava a logistika, 8(2), 30-38. $\quad \mathrm{http}: / /$ fpedas.utc.sk/zdal/images/zdal/archiv/ zdal_2012-02.pdf

[13] Leaflet UIC Code 406 - Capacity. $2^{\text {nd }}$ ed. Paris: International Union of Railways (UIC), 2013.

\section{Contact information:}

Jozef GAŠPARÍK, Assoc. Prof. Ing. PhD.

University of Žilina, Faculty of Operation an Economics of Transport and Communications, Department of Railway Transport,

Univerzitna 2, 01026 Žilina, Slovakia

E-mail: jozef.gasparik@fpedas.uniza.sk

Borna ABRAMOVIĆ, Assoc. Prof. PhD.

University of Zagreb,

Faculty of Transport and Traffic Sciences (FTTS)

Vukelićeva 4, PO. Box 170

HR-10000 Zagreb, Croatia

E-mail: borna.abramovic@fpz.hr

Vladislav ZITRICKÝ, Ing. PhD

University of Žilina, Faculty of Operation an Economics of Transport and Communications, Department of Railway Transport,

Univerzitna 2, 01026 Žilina, Slovakia

E-mail: vladislav.zitricky@fpedas.uniza.sk 